\title{
THE ROLE OF ENDOMETRIAL VOLUME IN THE PREDICTION OF ENDOMETRIAL HYPERPLASIA IN PERIMENOPAUSAL ABNORMAL UTERINE BLEEDING
}

\author{
By
Medhat Ramadan Abd El-Kawy, Mofeed Fawzy Mohammed and Wael Soliman Taha \\ Department of Obstetrics and Gynecology, Faculty of Medicine, Al-Azhar University, \\ Egypt \\ Corresponding author: Medhat Ramadan Abd El-Kawy, \\ E-mail: medhatmedicine2020@yahoo.com
}

\begin{abstract}
Background: Abnormal uterine bleeding (AUB) is a broad term that describes irregularities in the menstrual cycle involving frequency, regularity, duration, and volume of flow outside of pregnancy. The gold standard for diagnosis of AUB is the endometrial biopsy for accurate detection of the exact pathological cause for bleeding. However, due to the invasive nature of this procedure, most of the cases are not complaint for this technique. Ultrasonography is non-invasive technique for evaluating the endometrium. However, using this technique to measure the thickness of the endometrium itself is not sufficient. 3D Transvaginal ultrasound enables an assessment of uterine and endometrial volume.
\end{abstract}

Objective: To assess the accuracy of 3D trans-vaginal Ultrasound in diagnosis of endometrial hyperplasia in women with perimenopausal abnormal uterine bleeding.

Patients and methods: This was a cross sectional study that included 75 patients selected from outpatient clinic of Obstetrics and Gynecology at Al-Hussein Hospital, Cairo, Egypt, from January 2020 till January 2021. Detailed history was obtained and full examinations were done for every patient included in the study. In addition, transvaginal ultrasound was done and the endometrial volume was measured, then all patients were submitted to endometrial curettage.

Results: Adenocarcinoma was the most reported findings in 27 cases (36\%). The best cut-off value for classification of patients into those with benign endometrial pathology and those with endometrial hyperplasia or carcinoma using endometrial volume was an endometrial volume $>12.35 \mathrm{ml}$ with $74.1 \%$ sensitivity and $95.2 \%$ specificity. The best cut-off value for classification of patients into those with benign endometrial pathology or hyperplasia and those with endometrial carcinoma using endometrial volume was an endometrial volume $>12.25 \mathrm{ml}$ with $96.3 \%$ sensitivity and $100 \%$ specificity.

Conclusion: 3D ultrasound is a reasonably accurate, helpful and non-invasive tool for assessing the endometrium that could replace the endometrial biopsy.

Keywords: Abnormal Uterine Bleeding, Endometrial Volume, Endometrial Hyperplasia, Transvaginal, 3D ultrasound. 


\section{INTRODUCTION}

Abnormal uterine bleeding (AUB) is one of the most frequent reasons for a gynecological evaluation (Sweet et al., 2012). It can be caused by structural and nonstructural uterine disorders. According to FIGO system PALM-COEIN, the causes can be the following: polyp, adenomyosis, leiomyoma, malignancy, coagulopathy, ovulatory disfunction, endometrial, iatrogenic, or not yet classified (Munro et al., 2011). Although in most cases AUB is not linked to a malignant or premalignant lesion, it should not be underestimated (Bignardi et al., 2010).

With approaching to age of menopause, as ovarian function is declining, ovulation may not occur. The unopposed estrogen without progesterone will cause the uterine lining to thicken. This thickening will cause endometrial hyperplasia and carcinoma, polyps and fibroids may also cause changes in bleeding pattern (Nandi and Poretsky, 2013).

Endometrial sampling is the gold standard for diagnosing abnormalities in the endometrial tissues with sensitivity ranging from $85-95 \%$ (Holalkere et al., 2010). There is a growing trend to use noninvasive procedures such as transvaginal ultrasound (TVUS), to measure the endometrial thickness, diagnose dysfunctional uterine bleeding, adenomyosis, endometrial polyps and leiomyomas (Alcazar and Galvan, 2010).

Another important ability of 3D TVUS is volume calculation using the Virtual Organ Computer-aided Analysis (VOCAL) even in irregularly shaped structures. This method has been demonstrated to be more accurate than 2D-volume estimation (Goldstein, 2010). The differentiation between benign endometrial pathology, endometrial hyperplasia and carcinomas was not possible due to overlap in the endometrial thickness measurements. When 3D volume measurements were performed, the overlap was much smaller which significantly improved the diagnosis of cancer (Timmermans et al., 2010).

The aim of the present study was to assess the accuracy of 3D trans-vaginal Ultrasound in diagnosis of endometrial hyperplasia in women with perimenopausal abnormal uterine bleeding.

\section{PATIENTS AND METHODS}

This was a cross sectional study that included 75 patients selected from outpatient clinic of Obstetrics and Gynecology at Al-Hussein Hospital, Cairo, Egypt, from January 2020 till January 2021.

We included perimenopausal females in the age group 40-55 years and with symptoms of abnormal bleeding, e.g. menorrhagia, metrorrhagia, and polymenorrhea. The cases with the following conditions were excluded; general cause that can cause abnormal uterine bleeding, history of drug use that can cause vaginal bleeding, local cause of bleeding such as: cervical or vaginal lesion and history of recent hormonal contraception.

After approval from the local Ethical Scientific Committee of Faculty of Medicine, Al-Azhar University and obtaining an informed written consent from the patients included in the study, all 
cases were subjected to complete history taking and thorough full general and local pelvic examination. The patients underwent 3D-transvaginal ultrasonography measuring endometrial volume using VOCAL. 3D vaginal ultrasound was done to study uterine size and shape and endometrial volume and exclude any uterine or ovarian pathology.

Technique: With an empty bladder, the patients were examined at Dr/Samir Abbas unit at Al-Hussein Hospital by the same doctor in the lithotomy position using Vulson s6 sonar.

The 3D image was obtained by switching the $3 \mathrm{D}$ volume mode and defining the region of interest by a movable sector on the screen. This sector has the shape of a truncated cone which can be manipulated to ensure that the whole of the endometrial cavity was included in the volume sampling while the patient remain still and the probe is held stationary. Volume sampling lasted about 4 seconds, during that time the conventional 2D plane was rotated through 180 degrees with the rotation axis oriented exactly along the longitudinal axis of the vaginal probe.

The data were stored digitally on the internal disk drive for subsequent analysis after the ultrasound probe is removed. The 3D-data were retrieved and presented in multi-planer display mode which simultaneously displays 3 perpendicular planes on the screen.

The actual volume was calculated by the built-in computer program using the Virtual Organ Computer-aided Analysis (VOCAL). This was a rotational method based on rotation in given steps $(6,9,15,30)$ on a given orthogonal plane
(A,B or $\mathrm{C}$ ). The endometrial volume was measured in plane $\mathrm{A}$ by delineating the endometrial margin at the endometrialmyometrial interface from the fundus to the internal cervical OS in a number of parallel slices which are 1-2 mm apart.

Endometrial curettage: Endometrial curettage was performed using a sharpended curette under general anesthesia. The sample was placed in formalin $10 \%$ and sent for histopathological identification of the nature of the endometrium or of the pathological lesion. Pathological examination of the biopsy was done at Al-Hussien Hospital pathology department.

Sample size calculation: From a previous study by (Odeh et al., 2010), the percentage of women with endometrial hyperplasia or endometrial carcinoma is expected to be approximately $20.1 \%$ among those presenting with perimenopausal bleeding. Using endometrial volume as a predictor, this sample size of 75 patients would have a power of $80 \%$ to detect a difference of 0.228 between an area under the ROC curve (AUC) of 0.5 under the null hypothesis and an AUC of 0.728 under the alternative hypothesis.

\section{Statistical analysis:}

Data were coded and entered using the statistical package for the Social Sciences (SPSS) version 26 (IBM Corp., Armonk, NY, USA). Data were summarized using mean and standard deviation for quantitative variables and frequencies (number of cases) and relative frequencies (percentages) for categorical variables. Comparisons between groups were done using (ANOVA) with multiple comparisons post hoc test for quantitative 
variables. For comparing categorical data, Chi square test was performed. ROC curve was constructed with area under curve analysis performed to detect best cutoff value of endometrial volume for detection of cancer. P-values less than 0.05 were considered statistically significant.

\section{RESULTS}

According to the histopathological results, atrophic endometrium was detected in 14 cases $(18.7 \%)$, disordered proliferative endometrium in 7 cases (9.3\%), hyperplastic polyp in 8 cases (10.7\%), simple endometrial hyperplasia without atypia in 13 cases (17.3\%), complex endometrial hyperplasia and simple endometrial hyperplasia with atypia in 3 cases each (4\%) and adenocarcinoma was the most reported findings in 27 cases (36\%) (Table 1).

Table (1): Histopathological result distribution of the study group

\begin{tabular}{|c|c|c|}
\hline Histopathological results & Count & $\mathbf{\%}$ \\
\hline Atrophic endometrium & 14 & $18.7 \%$ \\
\hline Disordered proliferative endometrium & 7 & $9.3 \%$ \\
\hline Hyperplastic polyp & 8 & $10.7 \%$ \\
\hline simple endometrial hyperplasia without atypia & 13 & $17.3 \%$ \\
\hline complex endometrial hyperplasia & 3 & $4.0 \%$ \\
\hline simple endometrial hyperplasia with atypia & 3 & $4.0 \%$ \\
\hline Adenocarcinoma & 27 & $36.0 \%$ \\
\hline
\end{tabular}

There was a statistically significant difference between benign endometrium, endometrial hyperplasia and adenocarcinoma as regard of age, parity and endometrial volume $(p<0.001)$. There was no statistically significant difference between the cases in the three study groups as regards of BMI. By using intergroup significance, there was a statistically significant difference between cases with benign endometrium compared to endometrial hyperplasia and endometrial carcinoma as regard age, parity and endometrial volume. Also, there was a statistically significant difference between cases with endometrial hyperplasia and endometrial carcinoma as regard parity and endometrial volume, but no in age. The number of previous abortions was 8 $(38.1 \%)$ in cases with benign endometrial pathology, 10 cases $(37 \%)$ in cases with endometrial hyperplasia and 12 cases (44.4\%) in cases with adenocarcinoma. There was no statistically significant difference between the cases in the three study groups $(\mathrm{p}=0.838)$ (Table 2$)$. 
THE ROLE OF ENDOMETRIAL VOLUME IN THE PREDICTION...

Table (2): Characteristics of patients with benign endometrial pathology, endometrial hyperplasia, or endometrial carcinoma

\begin{tabular}{|c|c|c|c|c|c|c|c|c|}
\hline \multicolumn{2}{|c|}{ Parameters } & \multicolumn{2}{|c|}{$\begin{array}{c}\text { Benign } \\
\text { endometrial } \\
\text { pathology } \\
\mathrm{N}=\mathbf{2 9}\end{array}$} & \multicolumn{2}{|c|}{$\begin{array}{l}\text { Endometrial } \\
\text { hyperplasia } \\
\quad \mathrm{N}=19\end{array}$} & \multicolumn{2}{|c|}{$\begin{array}{c}\begin{array}{c}\text { Adenocarcinoma } \\
\mathbf{N}=27\end{array} \\
\end{array}$} & $\begin{array}{c}\mathbf{P} \\
\text { value }\end{array}$ \\
\hline \multicolumn{2}{|c|}{ AGE } & \multicolumn{2}{|c|}{$\begin{array}{c}48.48 \pm 1.54 \\
\mathrm{a}\end{array}$} & \multicolumn{2}{|c|}{$50.93 \pm 1.64 \mathrm{~b}$} & \multicolumn{2}{|c|}{$50.85 \pm 1.79 \mathrm{~b}$} & $<0.001$ \\
\hline \multicolumn{2}{|c|}{ BMI } & \multicolumn{2}{|c|}{$34.70 \pm 5.31$} & \multicolumn{2}{|c|}{$34.19 \pm 3.88$} & \multicolumn{2}{|c|}{$34.84 \pm 3.91$} & 46 \\
\hline \multicolumn{2}{|c|}{ Parity Median (IQR) } & \multicolumn{2}{|c|}{$4(3-5) a$} & \multicolumn{2}{|c|}{$3(2-4) b$} & \multicolumn{2}{|c|}{$2(1-2) c$} & 0.001 \\
\hline \multicolumn{2}{|c|}{$\begin{array}{l}\text { Endometrial Volume } \\
\text { (ml) by 3D vaginal US }\end{array}$} & \multicolumn{2}{|c|}{$9.78 \pm 1.77 \mathrm{a}$} & \multicolumn{2}{|c|}{$11.96 \pm 2.02 b$} & \multicolumn{2}{|c|}{$20.16 \pm 2.62 c$} & $<0.001$ \\
\hline \multirow{2}{*}{$\begin{array}{l}\text { Previous } \\
\text { Abortions }\end{array}$} & yes & 8 & $38.1 \%$ & 10 & $37.0 \%$ & 12 & $44.4 \%$ & \multirow{2}{*}{0.838} \\
\hline & no & 13 & $61.9 \%$ & 17 & $63.0 \%$ & 15 & $55.6 \%$ & \\
\hline
\end{tabular}

a, b, c: Similar letters indicate no statistically significant difference between the adjacent groups different letters indicate a statistically significant difference between the adjacent groups

The results of receiver-operating characteristic (ROC) curve analysis for classification of patients into those with benign endometrial pathology and those with endometrial hyperplasia or carcinoma using endometrial volume. The best cut-off value was an endometrial volume $>12.35 \mathrm{ml}$. This had a sensitivity of $74.1 \%$ and a specificity of 95.2 . This was highly statistically significant value ( $\mathrm{p}<0.001)$ and AUC (0.894) (Table 3 and Figure 1).

Table (3): Receiver-operating characteristic (ROC) curve analysis for classification of patients into those with benign endometrial pathology and those with endometrial hyperplasia or carcinoma using endometrial volume

\begin{tabular}{|c|c|c|c|c|c|c|}
\hline \multirow{2}{*}{$\begin{array}{c}\text { Area } \\
\text { Under the } \\
\text { Curve }\end{array}$} & \multirow[b]{2}{*}{$P$ value } & \multicolumn{2}{|c|}{ 95\% Confidence Interval } & \multirow[b]{2}{*}{$\begin{array}{c}\text { Cut } \\
\text { off }\end{array}$} & \multirow[b]{2}{*}{$\begin{array}{c}\text { Sensitivity } \\
\%\end{array}$} & \multirow[b]{2}{*}{$\begin{array}{c}\text { Specificity } \\
\%\end{array}$} \\
\hline & & $\begin{array}{l}\text { Lower } \\
\text { Bound }\end{array}$ & Upper Bound & & & \\
\hline 0.894 & $<0.001$ & 0.823 & 0.965 & 12.35 & 74.1 & 95.2 \\
\hline
\end{tabular}

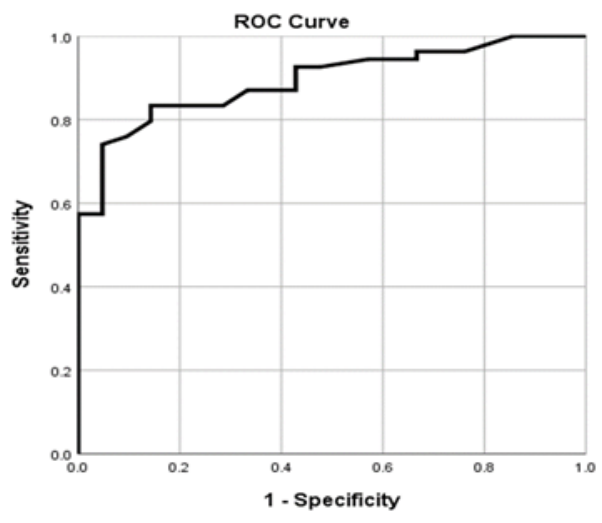

Figure (1): Receiver-operating characteristic (ROC) curve analysis for classification of patients into those with benign endometrial pathology and those with endometrial hyperplasia or carcinoma using endometrial volume 
The results of receiver-operating characteristic (ROC) curve analysis for classification of patients into those with benign endometrial pathology or hyperplasia and those with endometrial carcinoma using endometrial volume. The best cut-off value was an endometrial volume $>12.25 \mathrm{ml}$. This had a sensitivity of $96.3 \%$ and a specificity of $100 \%$. This was highly statistically significant value $(\mathrm{p}<0.001)$ and AUC (0.997) (Table 4 and Figure 2).

Table (4): Receiver-operating characteristic (ROC) curve analysis for classification of patients into those with benign endometrial pathology or hyperplasia and those with endometrial carcinoma using endometrial volume

\begin{tabular}{|c|c|c|c|c|c|c|}
\hline $\begin{array}{c}\text { Area } \\
\text { Under the } \\
\text { Curve }\end{array}$ & P value & \multicolumn{2}{|c|}{ 95\% Confidence Interval } & \multirow{2}{*}{ Cower } \\
\cline { 3 - 4 } & & $\begin{array}{c}\text { Upper } \\
\text { Bound }\end{array}$ & $\begin{array}{c}\text { Sensitivity } \\
\text { Bound }\end{array}$ & $\begin{array}{c}\text { Specificity } \\
\text { \% }\end{array}$ \\
\hline 0.999 & $<0.001$ & 0.997 & 1.000 & 15.25 & 96.3 & 100 \\
\hline
\end{tabular}

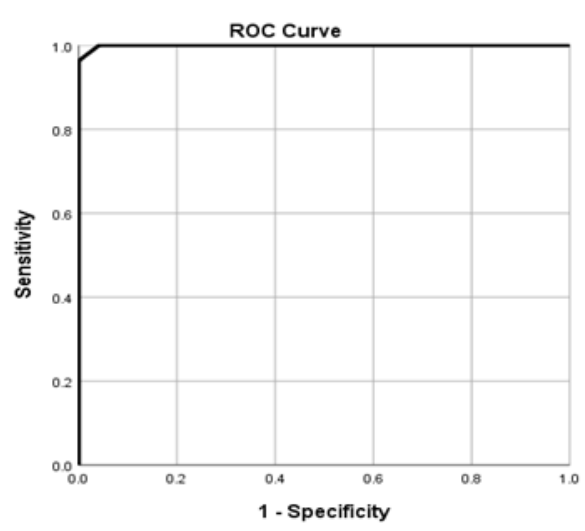

Figure (2): Receiver-operating characteristic (ROC) curve analysis for classification of patients into those with benign endometrial pathology or hyperplasia and those with endometrial carcinoma using endometrial volume

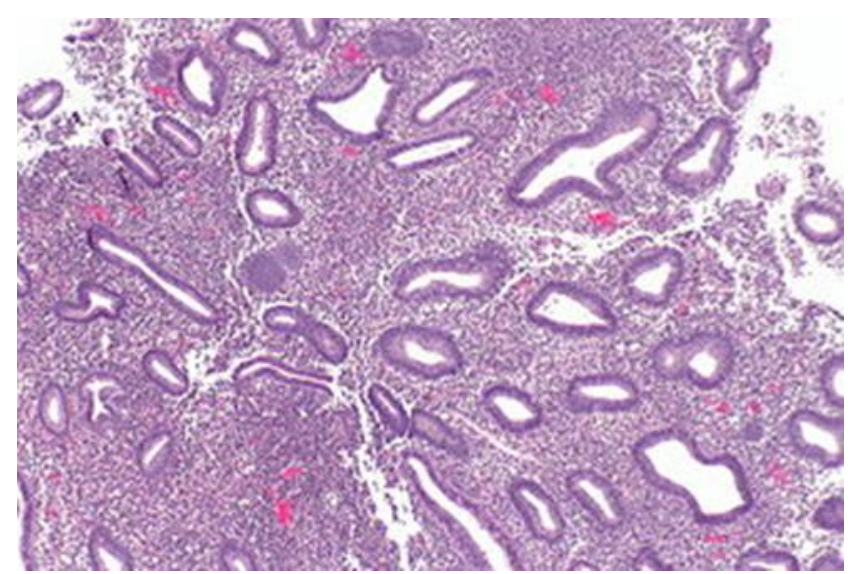

Figure (3): Ultrasound of endometrial hyperplasia: TVUS demonstrating a welldefined, thick and highly reflective layer occupying the whole of the endometrial cavity and surrounded by a symmetrical 
THE ROLE OF ENDOMETRIAL VOLUME IN THE PREDICTION...

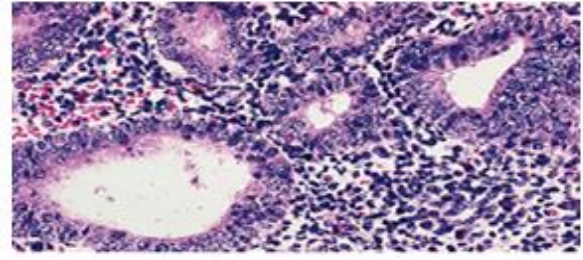

Figure (5): Microscopic picture of simple hyperplasia with atypia

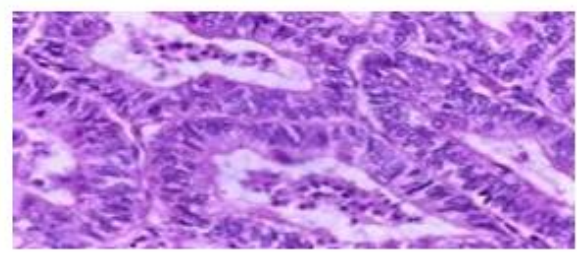

Figure (7): Microscopic picture of endometrioid adenocarcinoma

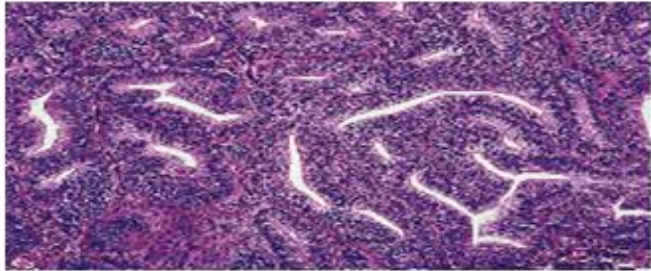

Figure (6): Microscopic picture of complex hyperplasia

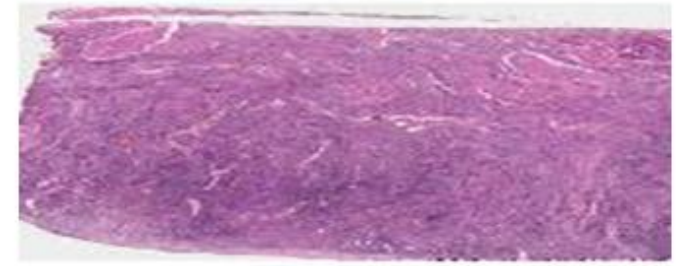

Figure (8): Microscopic picture of senile atrophic endometrium

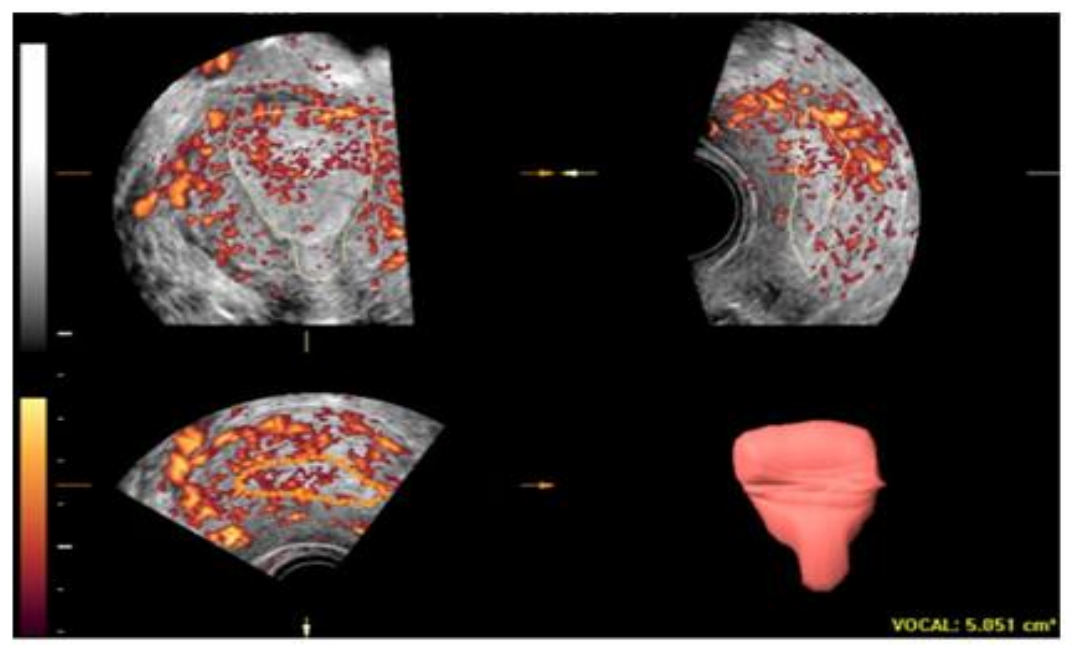

Figure (9): Endometrial volume by vocal technique.

\section{DISCUSSION}

In this study, we tried to assess the accuracy of 3D Trans-vaginal Ultrasound in diagnosis of endometrial hyperplasia with endometrial volume measurement in women with perimenopausal abnormal uterine bleeding.

According to the histopathological results, atrophic endometrium was detected in $18.7 \%$, disordered proliferative endometrium in $9.3 \%$, hyperplastic polyp in $10.7 \%$, simple endometrial hyperplasia without atypia in $17.3 \%$, complex endometrial hyperplasia and simple endometrial hyperplasia with atypia in $4 \%$ and adenocarcinoma was the most reported findings in $36 \%$.

Our results came in agreement with Elsokkary et al. (2016) stated that women with benign endometrial pathology were $29.33 \%$, which included atrophic and disordered proliferative endometrium. 
Women with endometrial hyperplasia were $36 \%$ which included hyper plastic polyp, simple endometrial hyperplasia without atypia and others with atypia and complex endometrial hyperplasia, while endometrial carcinoma was found in $34.67 \%$.

Our results disagreed with Nasir et al. (2010) who reported that women with benign endometrial pathology were $58.2 \%$, which included atrophic and disordered proliferative endometrium, while women with endometrial hyperplasia were $38.2 \%$ which included hyperplastic polyp, simple endometrial hyperplasia without atypia and others with atypia and complex endometrial hyperplasia while endometrial carcinoma was found in $3.6 \%$.

Our results also came in disagreement with Pyari et al. (2010) who showed that normal endometrium was found in $18 \%$, myomas in $32 \%$, endometrial polyps in $12 \%$, endometrial hyperplasia in $22 \%$, and endometrial carcinoma in $4 \%$.

Ebrashy et al. (2010) examined 65 cases by both TVS 2D and 3D ultrasound and the results are by 2D ultrasound: $20 \%$ are normal, $10.67 \%$ showing endometrial polyps, $44.61 \%$ having myomas either single or multiple, $18.46 \%$ had thickened endometrium while by 3D ultrasound: $13.84 \%$ are normal.

Odeh et al. (2010) evaluated the accuracy of endometrial volume measurement in the diagnosis of endometrial carcinoma and endometrial hyperplasia, and found that $17.9 \%$ of patients had an endometrial polyp, $12.5 \%$ had hyperplasia and $7.6 \%$ had endometrial carcinoma.
Our results contradicted those reported by Khare et al. (2012) and Damle et al. (2013). This could be explained as these results included only cases in premenopausal period and the incidence of carcinoma increase after menopause.

In this study, there was a statistically significant difference between benign endometrium, endometrial hyperplasia and adenocarcinoma as regard of age. There was a statistically significant difference between cases with benign endometrium compared to endometrial hyperplasia and endometrial carcinoma as regard age; however, there was a statistically significant difference between cases with endometrial hyperplasia and endometrial carcinoma. Nasir et al., (2010) reported that there was a statistically significant difference as regards the mean age between women with benign endometrial pathology compared to that of either endometrial hyperplasia or carcinoma. This came in agreement with Elsokkary et al. (2016) who reported that there was a statistically significant difference between benign endometrium compared to endometrial hyperplasia and to endometrial carcinoma as regard age.

In this study, there was a statistically significant difference between benign endometrium, endometrial hyperplasia and adenocarcinoma as parity. The median number of parity in cases with benign endometrial pathology was 4 (IQR $3-5)$, in cases with endometrial hyperplasia was 3 (IQR 2-4) and in cases with adenocarcinoma was 2 (IQR 1-2). The cases with benign conditions had higher number of parity. This came in accordance with Nasir et al. (2010) who 
showed that there was a statistically significant difference between benign endometrium compared to endometrial hyperplasia and to endometrial carcinoma as regard parity.

In this study, there was a statistically significant difference between benign endometrium, endometrial hyperplasia and adenocarcinoma as regard of endometrial volume. There was a statistically significant difference between cases with benign endometrium compared to endometrial hyperplasia and endometrial carcinoma and there was a statistically significant difference between cases with endometrial hyperplasia and endometrial carcinoma. This came in agreement with Nasir et al. (2010) who showed that the difference between patients with benign endometrium, compared to endometrial hyperplasia and endometrial carcinoma was highly statistically significant. Also, the difference between patients with benign endometrial pathology and endometrial hyperplasia compared to endometrial carcinoma was statistically significant. Also, Elsokkary et al. (2016) showed that there was a highly statistically significant difference between patients with benign endometrium, endometrial hyperplasia and endometrial carcinoma, as regarding endometrial volume.

A study was done by Gruboeck et al. (2010) analyzed the diagnostic value of endometrial volume in patients with postmenopausal bleeding for diagnosing endometrial cancer in women with postmenopausal bleeding. In patients with endometrial cancer. The endometrial volume and thickness were significantly lower in patient with benign lesions.
Thickness were the same in polyps and hyperplasia, however endometrial volume in hyperplasia was significantly higher than ployp. Galván et al. (2010) stated that EV and VI were related independently to myometrial infiltration and tumor stage in endometrial carcinoma; VI was associated alone with tumor grade and EV had a correlation with lymph node metastases.

Mansour and Co-workers (2011) assessed endometrial volume as a predictor of endometrial malignancy in women with postmenopausal bleeding. $50 \%$ of cases in the study group had benign disease, $35 \%$ had atypia and $15 \%$ had cancer.

Saarelainen et al. (2012) suggested that endometrial indices and EV correlate with the myometrial invasion depth of endometrial carcinoma. These results matched completely with our results.

El-Mekkawi et al. (2015) stated that $53.3 \%$ women had benign endometrial lesions, and $46.7 \%$ had endometrial malignancy. Women with malignancy tended to have significantly larger endometrial volume.

However, Elgarhy et al. (2019) reported in their study that endometrial volume was not significant in diagnosis of the endometrial cancer in women with postmenopausal bleeding ( $p$-value was $>0.05$ ). This could be explained as these results included only cases in postmenopausal period and our study in perimenopausal period.

In this study, according to the results of the receiver-operating characteristic (ROC) curve analysis for classification of patients into those with benign 
endometrial pathology and those with endometrial hyperplasia or carcinoma using endometrial volume. The best cutoff value was an endometrial volume $>12.35 \mathrm{ml}$. This had a sensitivity of $74.1 \%$ and a specificity of 95.2. This was a statistically significant value and AUC (0.894).

Also, our results showed that the results of receiver-operating characteristic (ROC) curve analysis for classification of patients into those with benign endometrial pathology or hyperplasia and those with endometrial carcinoma using endometrial volume. The best cut-off value was an endometrial volume $>12.25$ ml. This had a sensitivity of $96.3 \%$ and a specificity of $100 \%$. This was highly statistically significant and AUC (0.997). This came in accordance with Nasir et al. (2010) who showed that by the results of receiver-operating characteristic (ROC) curve analysis for classification of patients into those with benign endometrial pathology and those with endometrial hyperplasia or carcinoma using endometrial volume that endometrial volume had a good predictive value. The best cut-off value was an endometrial volume $>12.2 \mathrm{ml}$. Also, the results of receiver-operating characteristic (ROC) curve analysis for classification of patients into those with benign endometrial pathology or hyperplasia and those with endometrial carcinoma using endometrial volume had shown that endometrial volume had a very good predictive value. The best cut-off value was an endometrial volume $>13.1 \mathrm{ml}$.

Elsokkary et al. (2016) reported that according to the results of receiveroperating characteristic (ROC) curve analysis for classification of patients into those with benign endometrial pathology and those with endometrial hyperplasia or carcinoma that the best cut-off value was an endometrial volume $>13.2 \mathrm{ml}$. This had a sensitivity of $67.9 \%$, a specificity of 81.8 , a positive predictive value (PPV) of $90.0 \%$, and a negative predictive value (NPV) of $51.4 \%$. in the same study, the results of receiver-operating characteristic (ROC) curve analysis for classification of patients into those with benign endometrial pathology or hyperplasia and those with endometrial carcinoma revealed that the best cut-off value was an endometrial volume $>13.5 \mathrm{ml}$. This had a sensitivity of $100 \%$, a specificity of $75.5 \%$, a positive predictive value (PPV) of $68.4 \%$, and a negative predictive value (NPV) of $100 \%$.

Volume was more sensitive than thickness for predicting malignancy, and a cutoff value of $1.35 \mathrm{~mL}$ was found to provide the best sensitivity (Mansour et al. 2011).

\section{CONCLUSION}

Endometrial adenocarcinoma was the most cause of AUB among the cases included in the study. Increased age was associated with higher risk for adenocarcinoma while parity was associated with lower risk of endometrial carcinoma. 3D ultrasound is a reasonably accurate, helpful and non-invasive tool for assessing the endometrium that could replace the endometrial biopsy.

Acknowledgement: The authors like to thank Dr./ Mahmoud Ali Hassan, Lecturer of Patlology, Al-Azhar University for his studying the histopathological examination. 
THE ROLE OF ENDOMETRIAL VOLUME IN THE PREDICTION...

\section{REFERENCES}

1. Alcazar JL and Galvan R. (2010): Three-dimensional power Doppler ultrasound scanning for the prediction of endometrial cancer in women with postmenopausal bleeding and thickened endometrium. American Journal of Obstetrics and Gynecology, 200(1):44- 50.

2. Bignardi $T$, Van den Bosch $T$ and Condous G. (2010): Abnormal uterine and post-menopausal bleeding in the acute gynaecology unit. Best Practice \& Research Clinical Obstetrics \& Gynaecology, 23(5):595607.

3. Damle RP, Dravid N, Suryawanshi KH, Gadre AS, Bagale PS and Ahire N. (2013): Clinicopathological spectrum of endometrial changes in peri-menopausal and post-menopausal abnormal uterine bleeding: A 2 years study. Journal of Clinical and Diagnostic Research, 7(12):2774-78.

4. Ebrashy AN, Momtaz M, Shawky OA, Soliman EM and Maaty ZA. (2010): Three Dimentional Transvaginal ultrasound in the assessment of uterine lesions: when do we really need it? Gynecologic Oncology, 16(2):90-95.

5. Elgarhy EMT, Kassem MAE and Alzayat MAE. (2019): ThreeDimensional Endometrial Volume and Power Doppler Angiography for Prediction of Endometrial Carcinoma in Woman with Postmenopausal Bleeding. The Egyptian Journal of Hospital Medicine, 77(5):5542-8.

6. El-Mekkawi SF, Bahaa AM, Akl SA and Sorour RM. (2015): Three- dimensional power Doppler ultrasound with a three-dimensional multislice view: is it a new modality in endometrial evaluation in women with postmenopausal bleeding? Journal of Evidence-Based Women's Health Journal Society, 5(3):143-9.

7. Elsokkary M, Shafik A and Nader S. (2016): The Role of Endometrial Volume in the Prediction of Endometrial Hyperplasia. Obstet Gynecol Int J., 4(6):136-142.

8. Galván R, Mercé L, Jurado $M$, Mínguez J, López-García $G$ and Alcázar JL. (2010): Threedimensional power Doppler angiography in endometrial cancer: correlation with tumor characteristics. Ultrasound in Obstetrics and Gynecology, 35(6):723-9.

9. Goldstein SR. (2010): Modern evaluation of the endometrium. Obstetrics \& Gynecology, 116(1):16876.

10. Gruboeck K, Jurkovic D, Lawton F, Savvas M, Tailor A and Campbell S. (2010): The diagnostic value of endometrial thickness and volume measurements by three-dimensional ultrasound in patients with postmenopausal bleeding. Ultrasound in Obstetrics and Gynecology, 8(4):272-6.

11. Holalkere N-S, Katur AM and Lee SI. (2010): Issues in imaging malignant neoplasms of the female reproductive system. Current Problems in Diagnostic Radiology, 38(1):1-16.

12. Khare A, Bansal $R$, Sharma $S$, Elhence P, Makkar $\mathbf{N}$ and Tyagi $\mathbf{Y}$. 
(2012): Morphological spectrum of endometrium in patients presenting with dysfunctional uterine bleeding. People's J Sci Res., 5(2):13-6.

13. Mansour G, El-Lamie I, El-Kady M, El-Mekkawi S, Laban $M$ and AbouGabal A. (2011): Endometrial volume as predictor of malignancy in women with postmenopausal bleeding. International Journal of Gynecology \& Obstetrics, 99(3):206-10.

14. Munro MG, Critchley HO, Broder MS and Fraser IS. (2011): Disorders FWGoM. FIGO classification system (PALM-COEIN) for causes of abnormal uterine bleeding in nongravid women of reproductive age. International Journal of Gynecology \& Obstetrics, 113(1):3-13.

15. Nandi A and Poretsky L. (2013): Diabetes and the female reproductive system. Endocrinology and Metabolism Clinics, 42(4):915-46.

16. Nasir A, Boulware $D$, Kaiser $H$, Lancaster J, Coppola D and Smith P. (2010): Cyclooxygenase-2 (COX2) expression in human endometrial carcinoma and precursor lesions and its possible use in cancer chemoprevention and therapy. In Vivo, 21(1):35-43.

17. Odeh M, Vainerovsky I, Grinin V, Kais M, Ophir E and Bornstein J. (2010):

Three-dimensional endometrial volume and 3dimensional power Doppler analysis in predicting endometrial carcinoma and hyperplasia. Gynecologic Oncology, 106(2):348-53.

18. Pyari JS, Rekha S, Srivastava P, Goel $M$ and Pandey M. (2010): A comparative diagnostic evaluation of hysteroscopy, transvaginal ultrasonography and histopathological examination in cases of abnormal uterine bleeding. Journal of Obstetrics and Gynecology of India, 56(3):240-3.

19. Saarelainen $S$, Vuento $M$, Kirkinen $P$ and Mäenpää J. (2012): Preoperative assessment of endometrial carcinoma by threedimensional power Doppler angiography. Ultrasound in Obstetrics \& Gynecology, 39(4):466-72.

20. Sweet MG, Schmidt-Dalton TA, Weiss PM and Madsen KP. (2012): Evaluation and management of abnormal uterine bleeding in premenopausal women. American Family Physician, 85(1):35-43.

21. Timmermans A, Opmeer BC, Khan KS, Bachmann LM, Epstein E and Clark TJ. (2010): Endometrial thickness measurement for detecting endometrial cancer in women with postmenopausal bleeding: a systematic review and meta-analysis. Obstetrics \& Gynecology, 116(1):160-7. 
THE ROLE OF ENDOMETRIAL VOLUME IN THE PREDICTION...

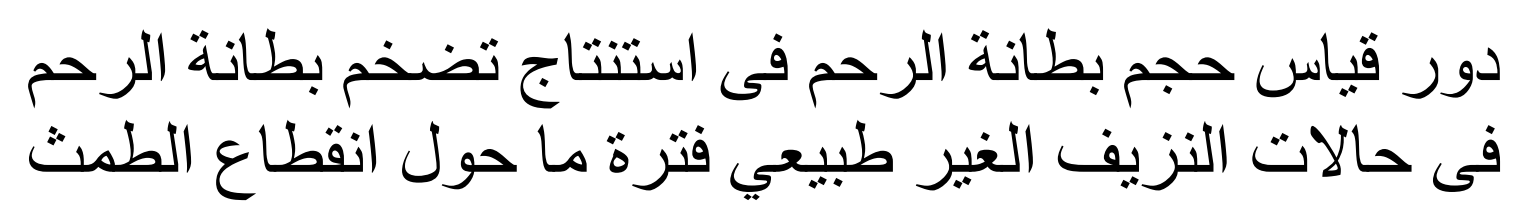

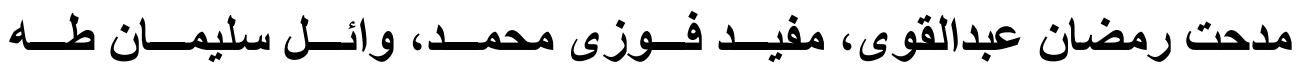

قسم التوليد و أمراض النساء، كلية الطب، جامعة الازهر

E-mail: medhatmedicine2020@yahoo.com

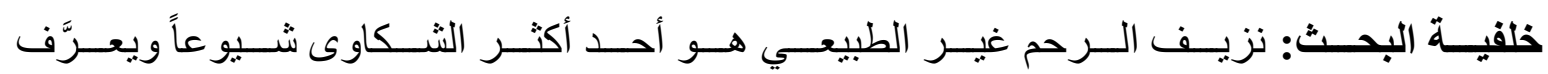

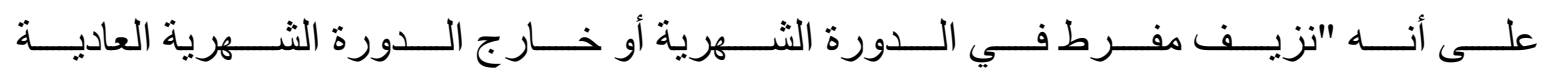

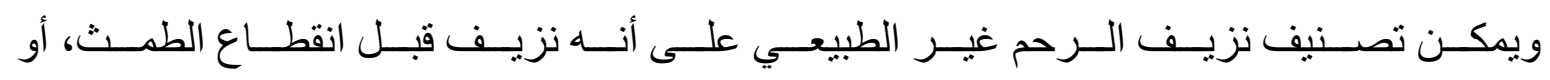

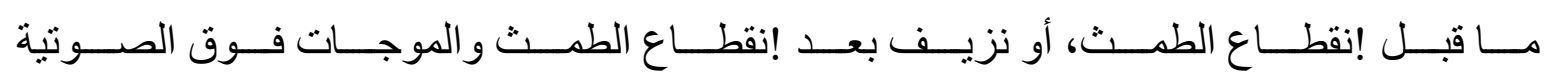

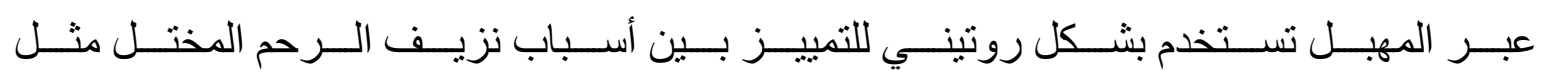

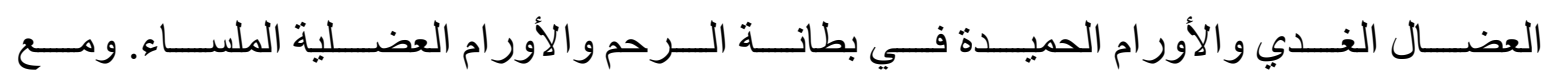

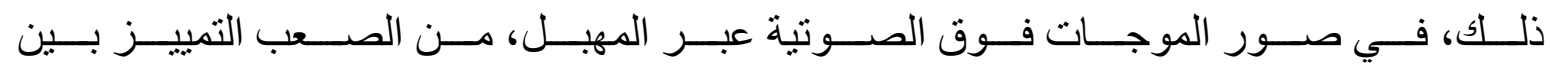

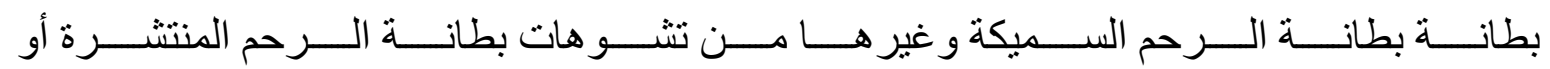
البؤرية.

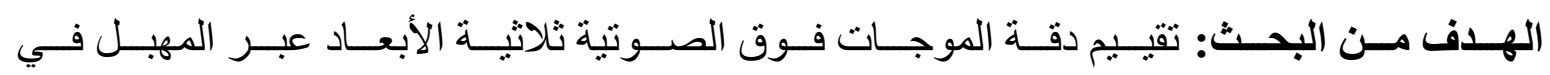

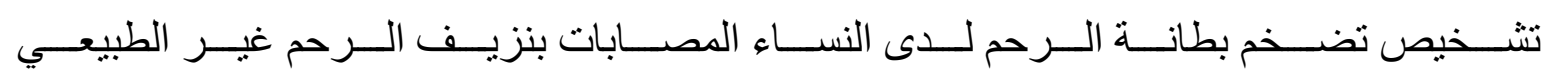
في فترة ما حول انقطاع الطمث.

المريضـــات وطــرق البحــث: هــذه در اســـة مقطعيـة شــملت 75 مريضـــة تــم إختيــار هن مــن

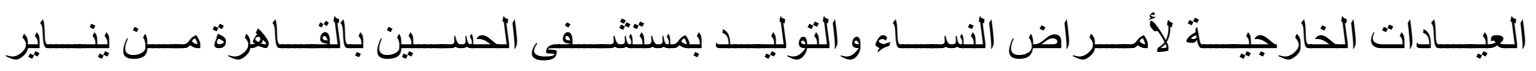
2020 حتــى ينــاير 2021. وجميــع الحــالات ناتجــة عـن نزيــف الــرحم غيــر الطبيعـي.

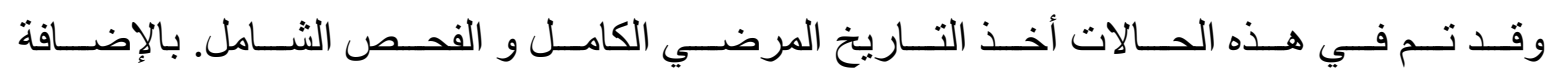

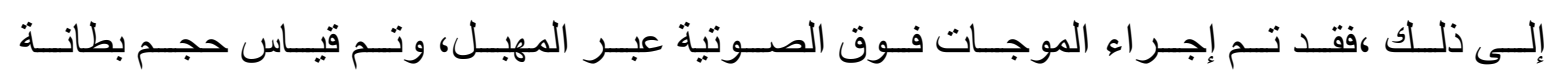
الرحم، ثم إخضاع جميع المرضى إلى كثط بطانة الرحم.

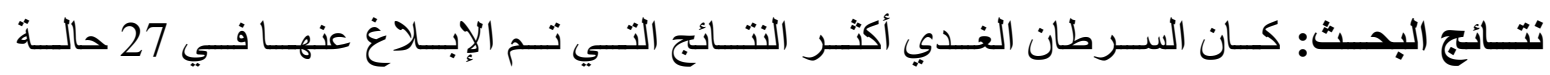

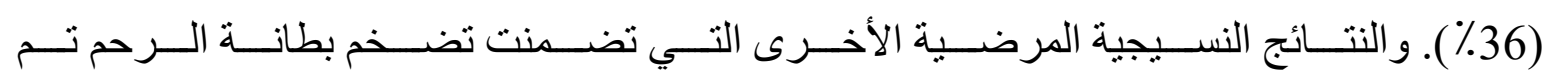

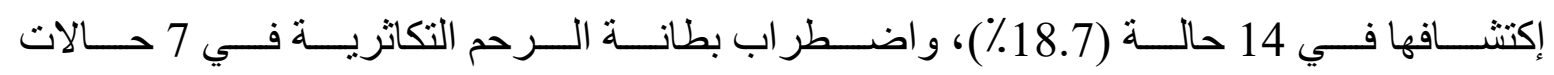




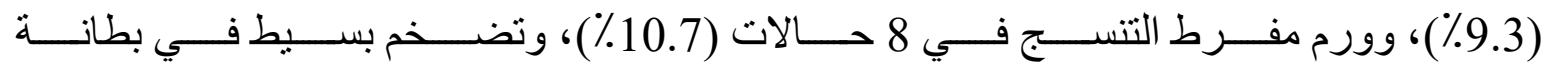

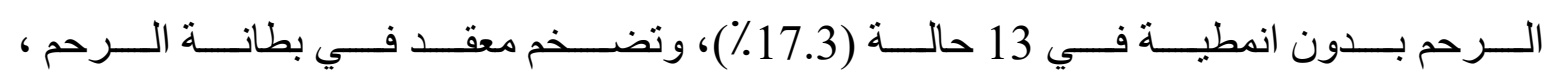

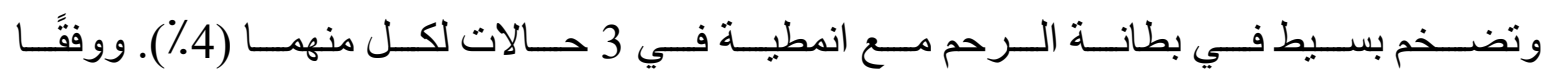

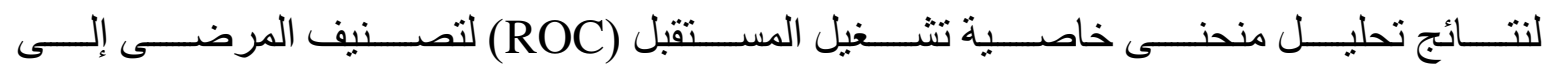

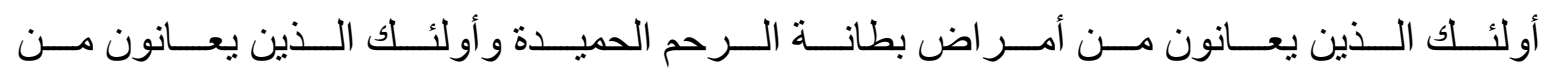

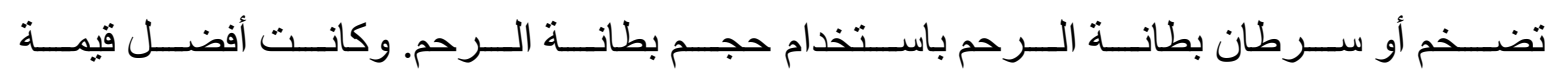

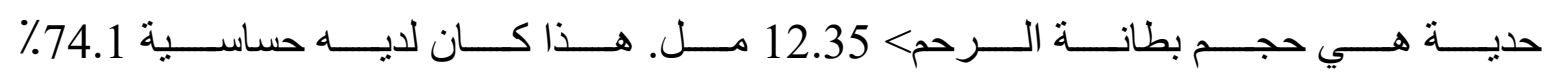

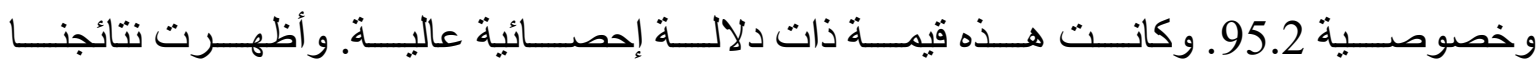

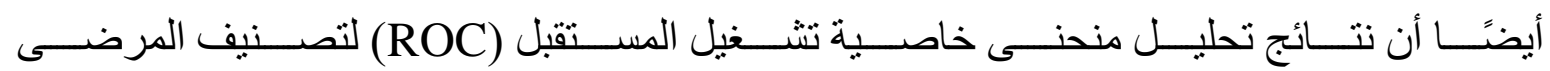

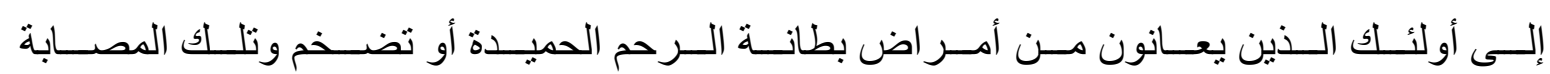

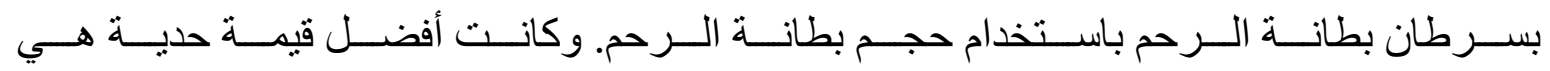

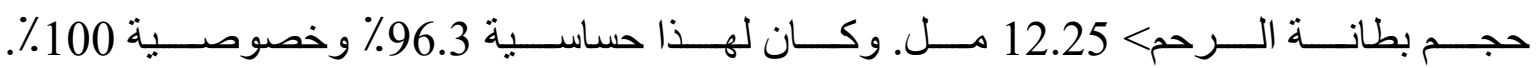
وكانت هذه القيم ذات دلالة إحصائية عالية.

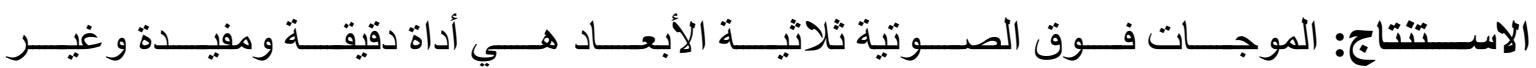

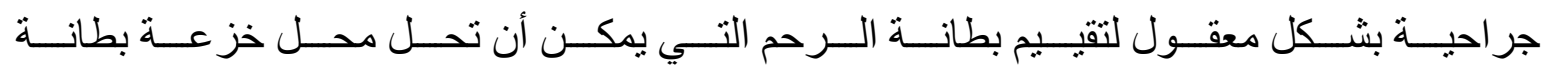
الرحم.

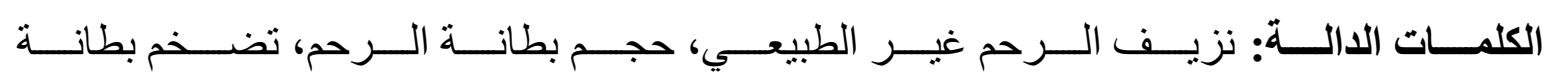
الرحم، المهيل، الموجات فوق الصوتية ثلاثية الأبعاد. 